\title{
Matrix Metalloproteinases in Necrotising Enterocolitis
}

\author{
SYLVIA LIN FOON PENDER, CHRISTIAN BRAEGGER, UTE GÜNTHER, \\ GIOVANNI MONTELEONE, MARTIN MEULI, DETLEF SCHUPPAN, AND \\ THOMAS THORNTON MACDONALD
}

\begin{abstract}
Division of Infection, Inflammation and Repair, University of Southampton School of Medicine, Southampton, SO16 6YD, UK [S.L.F.P., U.G., T.T.M]; Department of Paediatric Gastroenterology and Nutrition, University Children's Hospital, Steinwiesstrasse 75, CH-8032 Zurich, Switzerland [C.B., M.M.]; Cattedra di Gastroenterologia, Dipartimento di Medicina Interna, Universita Tor Vergata di Roma, Via Montpellier N.I., 00133 Rome, Italy [G.M.]; First Department of Medicine, University of Erlangen-Nürnberg, Krankenhausstrasse 12, 91054, Erlangen, Germany [D.S.]
\end{abstract}

\section{ABSTRACT}

\begin{abstract}
Elevated cytokines, especially TNF- $\alpha$, have been implicated in the pathogenesis of necrotising enterocolitis (NEC). We have previously shown that TNF- $\alpha$ drives the production of matrix degrading enzymes, the matrix metalloproteinases (MMPs), in the gut wall. In this study we have therefore investigated the role of MMPs in the pathogenesis of NEC in neonates. Nine newborn infant nonnecrotic resected bowels with confirmed NEC were studied and 8 newborn infants with neonatal bowel obstructions were used as controls. Immunostaining was used to identify the numbers of monocytes, macrophages, neutrophils, and T cells in the tissue. We used quantitative, competitive RT-PCR to analyze the number of TNF- $\alpha$, IFN- $\gamma$, MMP, and TIMP mRNA transcripts and western blotting to analyze MMP and TIMP protein production. Double labeling (immunostaining and in situ hybridization) was used to identify the phenotype of MMP mRNA expressing cells. We found increased numbers of monocytes, macrophages, and neutrophils in NEC tissue compared with controls. The number of T cells was unexpectedly
\end{abstract}

low in NEC as was the number of IFN- $\gamma$ transcripts in comparison with the control samples. Increased numbers of transcripts for TNF- $\alpha$ were detected in NEC tissue, as was mRNA expression and protein production for stromelysin-1 and TIMP-1 but not collagenase, gelatinases, or TIMP-2. The cellular source of stromelysin- 1 in NEC was $\alpha$-smooth muscle actin positive cells. These results suggest that stromelysin-1, which has the ability to degrade the mucosal extra-cellular matrix, may be responsible for the extensive tissue injury in infants with NEC. (Pediatr Res 54: 160-164, 2003)

$\quad$ Abbreviations
ECM, extra-cellular matrix
IFN- $\boldsymbol{\gamma}$, interferon gamma
MMP, matrix metalloproteinase
NEC, necrotising enterocolitis
TIMP, tissue inhibitor of metalloproteinase
TNF- $\boldsymbol{\alpha}$, tumour necrosis factor-alpha

Necrotizing enterocolitis is a severe disease and is the most common gastrointestinal emergency in the neonatal-intensive care unit. It predominantly affects premature infants of birth weight less than $1000 \mathrm{~g}$ and the onset of the disease is usually between the 3 rd and 10th days of life. It may present with a wide spectrum of signs, ranging from benign gastrointestinal disturbance to a rapidly fulminant course characterized by

Received July 3, 2002; accepted January 16, 2003.

Correspondence: Dr. Sylvia L.F. Pender, Division of Infection, Inflammation and Repair, Mailpoint 813, Level E, South Academic Block, Southampton General Hospital, Tremona Road, Southampton, SO16 6YD, UK; e-mail: s.pender@soton.ac.uk

Supported by the Hope Innovation Fund (F31), Wessex Medical Trust, Southampton, United Kingdom.

DOI: 10.1203/01.PDR.0000072326.23442.C3 intestinal gangrene, perforation, sepsis, and shock (1). The typical patient has abdominal distention, ileus with delayed gastric emptying, diarrhea, and abdominal tenderness as well as gastrointestinal bleeding. The disease is characterized by an extensive hemorrhagic inflammatory necrosis of the terminal ileum and ascending colon, although in severe cases the entire bowel may be involved. Pathologic examination shows that intramural hemorrhage, gangrene, peritonitis, and edema may progress to transmural "band" necrosis with extensive infiltration of neutrophils (1). Mortality is directly related to the presence of bacteremia, disseminated intravascular coagulation, ascites, and very low birth weight (2-4). Although numerous risk factors including prematurity, hypoxia, formula feeding, bacterial infection, and intestinal ischemia have been 
implicated in the pathogenesis of NEC, the etiology of the disease remains unclear.

We have previously shown that matrix metalloproteinases (MMPs), in particular stromelysin-1, are highly up-regulated in inflammatory bowel disease (5). Mechanistic studies using explant cultures of fetal human small intestine have clearly demonstrated that mucosal degradation following local immune activation is mediated by MMPs (6). MMPs are a group of zinc-dependent neutral endopeptidases collectively capable of degrading all components of the extra-cellular matrix (ECM) (7-9). The human MMP gene family contains at least 22 structurally related members (10). They are of pathologic significance in the ECM degradation seen in rheumatoid arthritis, osteoarthritis, periodontal disease, atherosclerosis, tumor cell invasion, and metastasis as well as in normal physiologic tissue remodeling, inflammation, and tumor spread $(11,12)$. Most of the enzymes involved are relatively substrate specific, secreted as inactive pro-enzymes and cleaved extra-cellularly to produce the active forms. The natural inhibitor of MMPs are the tissue inhibitor of metalloproteinases (TIMPs). The extra-cellular activity of MMPs is regulated by TIMPs, which are produced by the same cell types that produce MMPs (8).

NEC represents the most extreme form of mucosal degradation seen in any clinical condition. We have shown that TNF- $\alpha$ can dramatically increase the production of MMPs by stromal cells (6) and that local TNF- $\alpha$ concentrations are elevated in NEC (13-15), we have now gone on to show that MMPs are also over-expressed in NEC tissue and we provide evidence that excessive stromelysin-1 could in part explain the patho-physiologic inflammatory response in infants at the onset of NEC. To the best of our knowledge, this is the first study of MMPs in this severe gastrointestinal condition.

\section{METHODS}

Patients. Resection material was obtained from the University Children's Hospital, Zurich, Switzerland, over a period of 3 years. Only specimens that have been removed for clinical reasons and for routine histopathology were used in this study. Resected bowels from nine newborn infants with confirmed NEC (based on clinical diagnosis and histology) were studied. Seven of them were operated on within the first $10 \mathrm{~d}$ of life. Eight newborn infants with neonatal bowel obstruction, including intestinal atresia, were used. Most of these patients were 4-5 mo old at the time of the bowel resection. Nonnecrotic areas were resected and snap-frozen immediately with liquid nitrogen and stored at $-70^{\circ} \mathrm{C}$ for further analysis.

Immunohistochemistry. Five $\mu \mathrm{m}$ frozen sections were cut and stained with anti-CD3 (for T cells), anti-CD68 (for macrophages), anti-CD14 (for monocytes), and anti-neutrophil elastase (for neutrophils), all diluted 1 in 50, Dako Ltd, High Wycombe, U.K., by indirectimmunochemistry. The secondary antibody was conjugated with alkaline phosphatase and fast red was used as the substrate. The density of positive cells in the lamina propria was quantified by another investigator on coded slides using a Zeiss image analyzing system.
Quantification of cytokine and MMP mRNA. Competitive reverse transcriptase PCR was used to measure the absolute number of transcripts of cytokine, MMP, and TIMP genes per microgram of total RNA as previously described $(16,17)$.

In brief, $0.5 \mu \mathrm{g}$ of total RNA was used for first strand cDNA synthesis together with a serial dilution of synthetic RNA template which has encoded the cytokine, MMP, and TIMP primer sites. A competitive PCR was then performed after the standard RNA and test RNA were co-reverse transcribed using M-MLV reverse transcriptase (100 units, Life Technologies). The thermal cycle was programmed with a hot start at $94^{\circ} \mathrm{C}$ for $5 \mathrm{~min}$ followed by 35 cycles at $94^{\circ} \mathrm{C}$ for $1.5 \mathrm{~min}$, annealing at $58^{\circ} \mathrm{C}$ for $2 \mathrm{~min}$, followed by extension at $72^{\circ} \mathrm{C}$ for $3 \mathrm{~min}(18)$. PCR products were electrophoresed in $1.5 \%$ agarose gels containing $0.3 \mu \mathrm{g} / \mathrm{ml}$ ethidium bromide. Bands were visualized and their intensities were quantified by densitometry (Seescan 1D gel analysis package v1.00, Seescan, Cambridge, U.K.). The ratios of the band intensities of the PCR products from the standard RNA and the target RNA were plotted against the starting amount of standard RNA molecules on a semilogarithmic scale. Preliminary experiments have shown that the mRNAs detected are at linear phase but not on a plateau. This technique allows us to quantify the number of cytokines or MMP transcripts in a tissue sample down to 1,000 transcripts per microgram of total RNA.

Western blotting. Western blotting was conducted on tissue lysates from control and NEC samples $\left(6 \mathrm{M}\right.$ urea, $5 \mathrm{mM} \mathrm{CaCl}_{2}$ and $50 \mathrm{mM}$ Tris, $\mathrm{pH} 7.4$ ) according to the methods described previously (5). In all cases, $150 \mu \mathrm{g}$ of protein was loaded onto each lane of the 10\% SDS-PAGE and ran in SDS-Tris-glycine running buffer under reducing conditions. Ponceau S solution was used to reveal the uniformity of protein loading onto gels. The primary antibodies used were sheep anti-human stromelysin-1 (1 in 500 dilution, The Binding Site Ltd, Birmingham) and mouse anti-human TIMP-1 $(1 \mu \mathrm{g} / \mathrm{mL}, \mathrm{CN}$ Biosciences UK, Nottingham). Rabbit anti-sheep (1 in 2500 dilution, Dako Ltd, Ely, Cambridgeshire) or rabbit anti-mouse (1 in 1000 dilution) antibodies were conjugated to horseradish peroxidase and were used as secondary antibodies. The reactions were developed with the ECL-plus kit (Amersham Pharmacia Biotech UK Ltd, Amersham Place, Buckinghamshire).

Identification of matrix metalloproteinase mRNA expressing cells by in situ hybridization. In situ hybridization combined with immunohistochemical staining to define the phenotype of the MMP mRNA expressing cells was performed. Immunohistology was performed immediately before prehybridization using ribonuclease-free buffers and glassware. Sections were stained with MAb specific for CD3 (UCHT-1, Dako Ltd), smooth muscle $\alpha$-actin (IA4, Sigma Chemical Co.), neutrophil elastase (Dako Ltd) and the monocyte/macrophage antigen CD68 (PG-M1, Dako Ltd) using the immunoalkaline phosphatase (APAAP) method with affinity-purified rabbit anti-mouse immunoglobin antibodies (Dako Ltd), APAAP complex (1:20 dilution, Dako Ltd), and new fuchsin. In situ hybridization was performed on fresh-frozen tissue sections with 35S-labeled MMP-3-specific riboprobes. Prehybridization washing procedures including removal of nonspecifically bound probe by RNAse A digestion, and autoradiography of 
slides were carried out as described previously $(19,20)$. As controls, sense probes to MMP-3 were used as well as an antisense probe to pro-collagen $\alpha 1$ (I).

Statistical tests. The significance of the data were analyzed by the Mann-Whitney U test using the SPSS statistics program version 10 (SPSS Inc., Chicago, IL, U.S.A.).

\section{RESULTS}

Characteristics of inflammatory cells in NEC. Nonnecrotic NEC samples were used in this study for they might reveal the mechanism of the development of NEC. Immunohistochemistry was performed in full thickness frozen sections of NEC and control samples. Confirming previous studies, we found that the number of neutrophils in NEC samples was significantly higher than that in the control samples $(p=0.002$ in the submucosa and $p=0.001$ in the mucosa), Fig. $1 A$. We also observed that the numbers of CD68 and CD14 positive cells were increased in full thickness NEC tissue samples compared with controls (Fig. $1 B$ and $C$ ). CD3 positive cells were present in all the control samples tested. However, CD3 positive cell densities were low in the mucosa of NEC ( $p=0.005)$, Fig. $1 D$. In addition, increased numbers of neutrophils, CD68+ and CD14+ positive cells were seen in both mucosa and submucosa of NEC samples (Fig. 2). Neutrophils and CD68 positive cells were not localized in the same areas.

Cytokines in NEC. The numbers of transcripts for IFN- $\gamma$ and TNF- $\alpha$ in the control samples were low with a median of 2,764 and 276, respectively. The median number of IFN- $\gamma$ transcripts in NEC was decreased to 567 transcripts per $\mu \mathrm{g}$ of total RNA $(p<0.03)$ whereas that of TNF- $\alpha$ was increased to 2455 transcripts per $\mu \mathrm{g}$ of total RNA $(p<0.03)$ (Fig. $3 A$ and $B$ ).

MMPs and TIMPs in NEC. Control samples contained transcripts for gelatinase A, stromelysin-1, TIMP-1 and TIMP-2 but the numbers of interstitial collagenase and gelati-

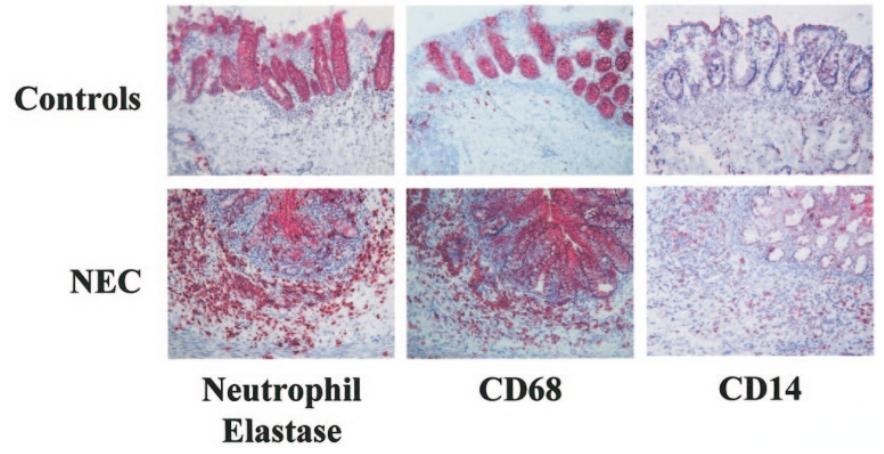

Figure 2. Immunostaining of neutrophils, CD68+ and CD14+ cells in nonnecrotic NEC and control samples. PBS is negative control. The red staining shows the positive cells. These are representative of 9 NEC and 8 controls (magnification $\times 100$ of the original).

nase B transcripts were low or absent. Both stromelysin-1 ( $p=$ $0.027)$ and TIMP-1 $(p=0.043)$ transcripts were significantly higher in NEC than in control samples, whereas there was no significant difference in the number of transcripts for interstitial collagenase, gelatinase A, gelatinase B, or TIMP-2 (Table 1).

We then determined whether the up-regulation of stromelysin-1 and TIMP-1 mRNA transcripts in NEC was reflected in increased protein production. Immunoreactive bands for prostromelysin-1 $(60 \mathrm{kD})$ were readily detected in the tissue lysates of the control samples (Fig. 4). The intensity of this band was stronger in most of the NEC tissue samples than in the controls. Additional bands corresponding to the active forms of stromelysin-1 $(54,50,44$ and $36 \mathrm{kD})$ were found in all tissue samples of NEC. Only trace amounts of these active forms were found in the control samples.

TIMP-1 protein was detected in low amounts in controls while like stromelysin-1, there was an up-regulation of TIMP-1 production in the NEC samples. Culture supernatants of fetal
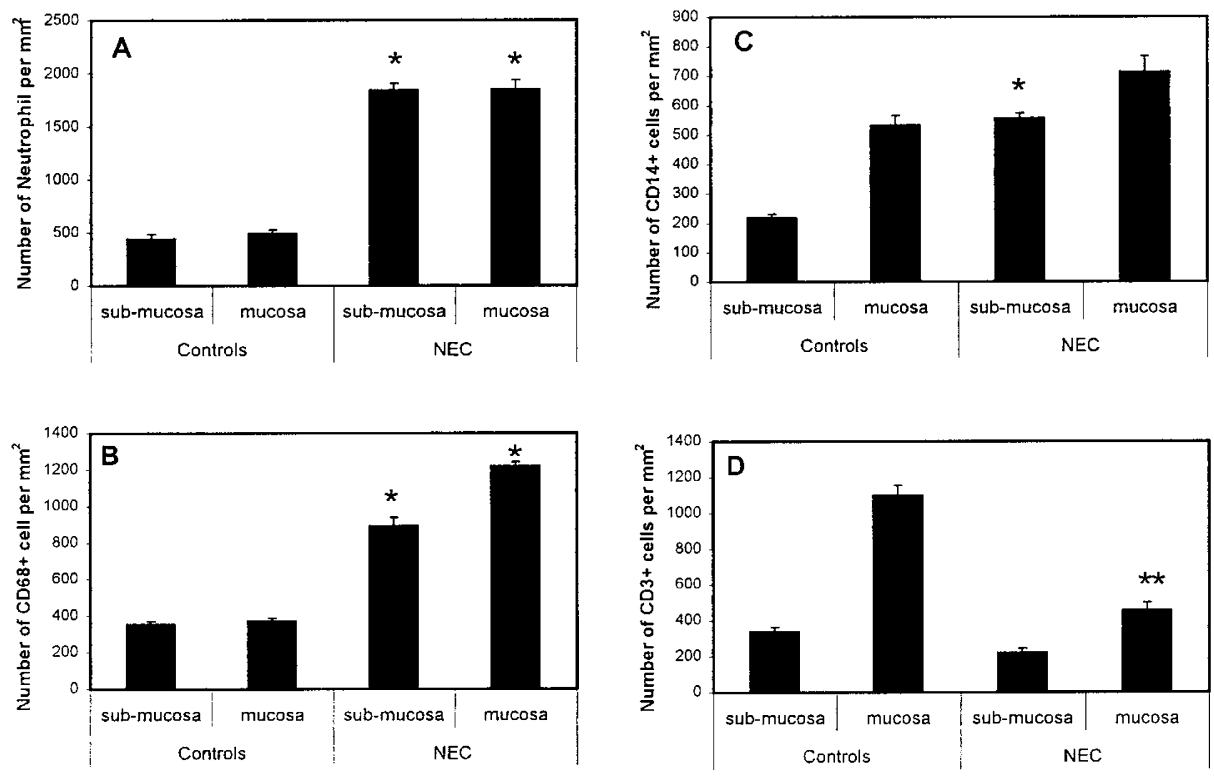

Figure 1. Densities of (A) neutrophils (B) macrophages (C) monocytes and (D) T cells in the sub-mucosa and mucosa of NEC and controls. $\left({ }^{*} p<0.005\right.$, $* * p$ $<0.01$ control vs NEC, $t$ test). 

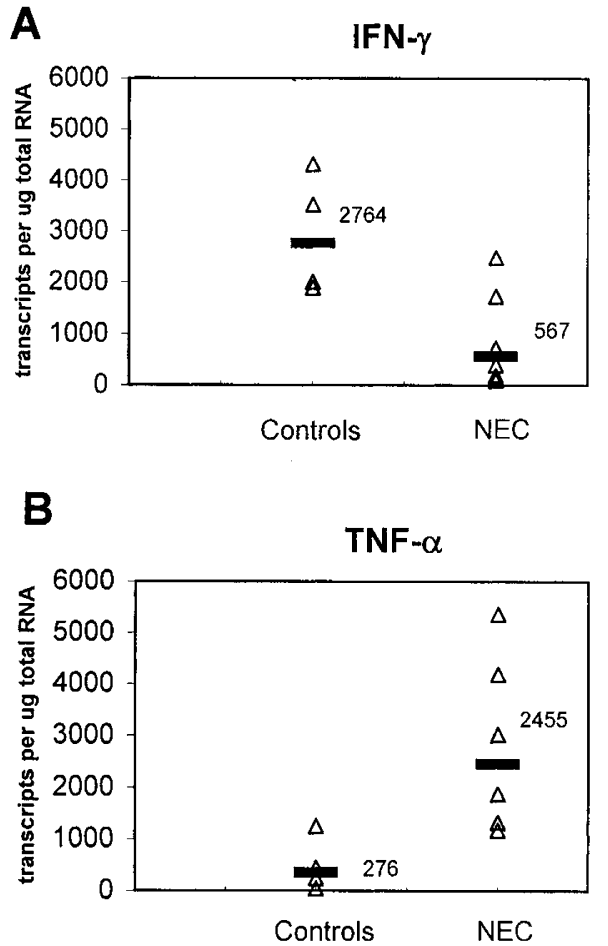

Figure 3. Competitive and quantitative RT-PCR. Both IFN- $\gamma$ and TNF- $\alpha$ were at relatively low levels in control samples. The number of (A) IFN- $\gamma$ transcripts was decreased in NEC, $p=0.03$, 2-tailed Mann-Whitney U test however (B) TNF- $\alpha$ transcripts was increased in NEC, $p=0.03$, 2-tailed Mann-Whitney U test. (Bars show the median).

gut mesenchymal cells stimulated with TNF- $\alpha$ (21) were used as positive controls (Fig. 4).

Identifying the cellular source of stromelysin-1 in NEC. Frozen sections were immunostained with MAb to cell specific markers and then the stromelysin- 1 mRNA expressing cells were detected by in situ hybridization on the same sections. Stromelysin-1 mRNA was detected in the tissue sections from the subjects with NEC. The cells expressing the mRNA did not stain with antibodies against $\mathrm{T}$ cells, monocytes, macrophages nor neutrophils. However, the cells did react to anti- $\alpha$-smooth muscle actin. These spindle-like cells located between the mucosa and sub-mucosa margin plate (Fig. 5). This is exactly the same pattern of stromelysin- 1 expressing cells as seen in inflammatory bowel disease (22).

\section{DISCUSSION}

In this study, we have presented evidence that monocytes, macrophages and neutrophils are increased in the mucosa and

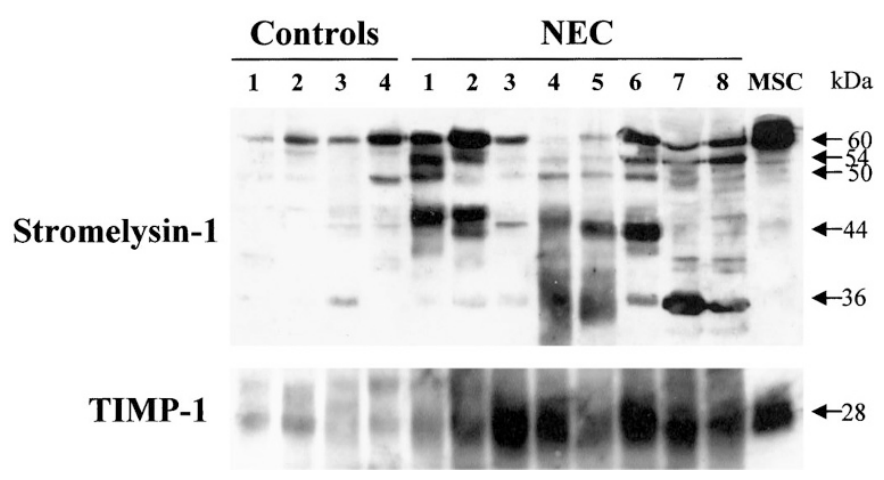

Figure 4. Western blotting for stromelysin-1 and TIMP-1 production in control and NEC samples. MSC is a positive control which is culture supernatant of fetal gut mesenchymal cells stimulated with TNF- $\alpha$. These are representative of 9 NEC and 8 controls.

submucosal areas of NEC. Increased transcripts for TNF- $\alpha$ are detected in NEC tissue as well as increased mRNA expression and protein production for stromelysin-1 and TIMP-1. The cellular source of stromelysin- 1 is mainly $\alpha$-smooth muscle actin positive cells localized between the mucosa and submucosa margin plate.

Both latent and active forms of stromelysin- 1 were increased in NEC compare with the controls. We have shown previously that nano-molar concentrations of recombinant stromelysin- 1 can completely degrade fetal gut explants within $24 \mathrm{~h}$ (6). In children with inflammatory bowel disease, large amounts of this enzyme were also found in inflamed bowel (5). In IBD, there is no change in TIMP-1 production in controls or in diseased tissue. But in NEC, we found that both TIMP-1 mRNA expression and protein production are significantly higher than in the controls. We think this is an important homeostatic mechanism and that the damaged neonatal tissue is trying to repair itself.

Our previous studies have shown that the production of MMPs by human fetal gut myofibroblasts is TNF- $\alpha$ dependent $(6,21)$. In this study, we found significantly increased numbers of TNF- $\alpha$ transcripts in NEC samples compared with controls. However, the number of transcripts detected in NEC was still relatively low in comparison to that of patients with IBD using the same methodology (5). This low level of TNF transcripts could be related to the mutations in TNF AU-rich elements (ARE). The deletion of the TNF ARE sequence has recently been shown to regulate the translational activation of the TNF message hence the TNF biosynthesis in mice (23). This deregulation resulted in the development of chronic inflammatory arthritis and inflammatory bowel disease, suggesting a possible link between a defective function of the ARE regulatory machin-

Table 1. Number of MMP and TIMP transcripts in controls and necrotising enterocolitis

\begin{tabular}{lcc}
\hline & \multicolumn{2}{c}{ Median number of transcripts per ug RNA (range) } \\
\cline { 2 - 3 } \multicolumn{1}{c}{ MMPs/TIMPs } & Controls $[\mathrm{n}=8]$ & $216(0-103,444)$ \\
Interstitial Collagenase & $556(0-56,035)$ & $\mathrm{n}=9]$ \\
Gelatinase A & $6,481(54-407,083)$ & $8,516(211-143,104)$ \\
Stromelysin-1 & $3,480(711-6,380)$ & $29,703(0-264,585)^{*}$ \\
Gelatinase B & $42(0-28,451)$ & $69(0-125,773)$ \\
TIMP-1 & $19,429(820-676,962)$ & $222,669(3,285-19,691,101)^{*}$ \\
TIMP-2 & $364,510(72,100-9,728,284)$ & $419,976(4,028-5,270,048)$ \\
\hline
\end{tabular}

* Mann-Whitney U, 2-tailed ( $p<0.05)$, NEC $v s$ controls. 


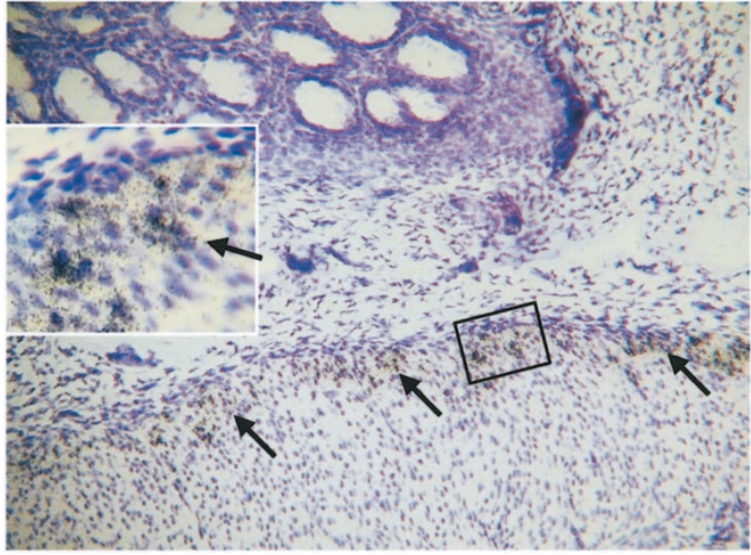

Figure 5. In-situ hybridization of stromelysin-1 in nonnecrotic NEC. The insert shows a close-up of stromelysin-1 positive cells (with gray granules) which are spindle shape, fibroblast-like cells. Arrows show the positive cells were located at the margin between the sub-mucosa and smooth muscle area. This is a representative of 4 samples. (magnification, main figure $\times 100$, insert $\times 400$ of the original).

ery and the development of analogous pathologies in humans (23). And this is likely to be the reason why we could only detect a relatively low level of TNF- $\alpha$ mRNA in resected bowel from infants with NEC. In this study, we have shown that the number of IFN- $\gamma$ transcripts was decreased in NEC. This differs from previously reported data $(24,25)$. We used an mRNA plasmid to measure IFN- $\gamma$ transcripts quantitatively, a method that can detect subtle changes more accurately than semi-quantitative RT-PCR. There are conflicting reports that preterm cells produce more or less inflammatory mediators than term newborns (26). In this study, the control tissue used was slightly older (4-5 mo old at the time of the bowel resection) than the preterm NEC tissue. Moreover, our results correspond to the decreased number of $\mathrm{T}$ cells detected in the mucosa of NEC, suggesting an impairment in the immune response in NEC neonates who would be unable to clear bacterial infections and would accumulate bacterial by-products in the gut. It has been shown that excessive bacterial metabolites in the intestine may cause an inflammatory condition resembling $\operatorname{NEC}(27,28)$. N-Butyrate, a bacterial by-product derived from the bacterial metabolism of unabsorbed carbohydrate may increase the risk of NEC (29). Indeed, it has been shown that butyrate can selectively up-regulate the mRNA expression and protein production of stromelysin-1 in fetal gut myofibroblasts (30). This matrix degrading enzyme has a broad substrate spectrum and is capable of causing severe tissue damage in the gut (6).

The infiltration of huge numbers of monocytes, macrophage and neutrophils into the mucosa and submucosa might be a secondary response to the bacterial invasion and tissue inflammation. We found increased numbers of macrophages and neutrophils in the mucosa and submucosa areas. This may indicate the presence of other MMPs, such as neutrophil elastase and macrophage metalloelastase.

The data here together with that of many others show that the impairment of immune response in the immature gut encourages bacteria and that the bacterial by-products synergise with TNF- $\alpha$, leading to the production of stromelysin-1 which causes severe tissue inflammation in the gut.
Acknowledgments. We thank Professor Martin Kagnoff, University of California at San Diego for a cytokine template and Dr. G. Schultz, University of Florida, for an MMP template (National Eye Institute Grant EY-05587).

\section{REFERENCES}

1. Kliegman RM, Fanaroff AA 1984 Necrotizing enterocolitis. N Engl J Med 310:10931103

2. Wilson R, Kanto WP, Jr., McCarthy BJ, Burton T, Lewin P, Terry J, Feldman RA 1981 Epidemiologic characteristics of necrotizing enterocolitis: a population-based study. Am J Epidemiol 114:880-887

3. Stoll BJ, Kanto WP, Jr., Glass RI, Nahmias AJ, Brann AW, Jr 1980 Epidemiology of necrotizing enterocolitis: a case control study. J Pediatr 96:447-451

4. Kliegman RM 1979 Neonatal necrotizing enterocolitis: implications for an infectious disease. Pediatr Clin North Am 26:327-344

5. Heuschkel RB, MacDonald TT, Monteleone G, Bajaj-Elliott M, Smith JA, Pender SL 2000 Imbalance of stromelysin-1 and TIMP-1 in the mucosal lesions of children with inflammatory bowel disease. Gut 47:57-62

6. Pender SL, Tickle SP, Docherty AJ, Howie D, Wathen NC, MacDonald TT 1997 A major role for matrix metalloproteinases in $\mathrm{T}$ cell injury in the gut. $\mathrm{J}$ Immunol 158:1582-1590

7. Murphy G, Docherty AJ 1992 The matrix metalloproteinases and their inhibitors. Am J Respir Cell Mol Biol 7:120-125

8. Birkedal-Hansen H, Moore WG, Bodden MK, Windsor LJ, Birkedal-Hansen B, DeCarlo A, Engler JA 1993 Matrix metalloproteinases: a review. Crit Rev Oral Biol Med 4:197-250

9. Nagase H, Woessner JF 1999 Matrix metalloproteinases. J Biol Chem 274:21491-21494

10. de Coignac AB, Elson G, Delneste Y, Magistrelli G, Jeannin P, Aubry JP, Berthier O, Schmitt D, Bonnefoy JY, Gauchat JF 2000 Cloning of MMP-26 A novel matrilysinlike proteinase. Eur J Biochem 267:3323-3329

11. Brown PD 1998 Matrix metalloproteinases in gastrointestinal cancer. Gut 43:161-163

12. Kahari VM, Saarialho-Kere U 1999 Matrix metalloproteinases and their inhibitors in tumour growth and invasion. Ann Med 31:34-45

13. Caplan MS, Hsueh W 1990 Necrotizing enterocolitis: role of platelet activating factor, endotoxin, and tumor necrosis factor. J Pediatr 117:S47-S51

14. Harris MC, Costarino AT, Jr., Sullivan JS, Dulkerian S, McCawley L, Corcoran L, Butler S, Kilpatrick L 1994 Cytokine elevations in critically ill infants with sepsis and necrotizing enterocolitis. J Pediatr 124:105-111

15. Morecroft JA, Spitz L, Hamilton PA, Holmes SJ 1994 Plasma cytokine levels in necrotizing enterocolitis. Acta Paediatr Suppl 396:18-20

16. Jung HC, Eckmann L, Yang SK, Panja A, Fierer J, Morzycka-Wroblewska E, Kagnoff MF 1995 A distinct array of proinflammatory cytokines is expressed in human colon epithelial cells in response to bacterial invasion. J Clin Invest 95:55-65

17. Monteleone G, MacDonald TT, Wathen NC, Pallone F, Pender SL 1999 Enhancing Lamina propria Th1 cell responses with interleukin 12 produces severe tissue injury. Gastroenterology 117:1069-1077

18. Tarnuzzer RW, Macauley SP, Farmerie WG, Caballero S, Ghassemifar MR, Anderson JT, Robinson CP, Grant MB, Humphreys-Beher MG, Franzen L, Peck AB, Schultz GS 1996 Competitive RNA templates for detection and quantitation of growth factors, cytokines, extracellular matrix components and matrix metalloproteinases by RT-PCR. Biotechniques 20:670-674

19. Herbst H, Wege T, Milani S, Pellegrini G, Orzechowski HD, Bechstein WO, Neuhaus P, Gressner AM, Schuppan D 1997 Tissue inhibitor of metalloproteinase-1 and -2 RNA expression in rat and human liver fibrosis. Am J Pathol 150:1647-1659

20. Milani S, Herbst H, Schuppan D, Surrenti C, Riecken EO, Stein H 1990 Cellular localization of type I III and IV procollagen gene transcripts in normal and fibrotic human liver. Am J Pathol 137:59-70

21. Pender SL, Fell JM, Chamow SM, Ashkenazi A, MacDonald TT 1998 A p55 TNF receptor immunoadhesin prevents $\mathrm{T}$ cell-mediated intestinal injury by inhibiting matrix metalloproteinase production. J Immunol 160:4098-4103

22. Pender SL, Breese EJ, Gunther U, Howie D, Wathen NC, Schuppan D, MacDonald TT 1998 Suppression of T cell-mediated injury in human gut by interleukin-10: role of matrix metalloproteinases. Gastroenterology 115:573-583

23. Kontoyiannis D, Pasparakis M, Pizarro TT, Cominelli F, Kollias G 1999 Impaired on/off regulation of TNF biosynthesis in mice lacking TNF AU-rich elements: implications for joint and gut-associated immunopathologies. Immunity 10:387-398

24. Ford HR, Sorrells DL, Knisely AS 1996 Inflammatory cytokines, nitric oxide, and necrotizing enterocolitis. Semin Pediatr Surg 5:155-159

25. Ford H, Watkins S, Reblock K, Rowe M 1997 The role of inflammatory cytokines and nitric oxide in the pathogenesis of necrotizing enterocolitis. J Pediatr Surg 32:275-282

26. Jurges ES, Henderson DC 1996 Inflammatory and immunological markers in preterm infants: correlation with disease. Clin Exp Immunol 105:551-555

27. Clark DA, Thompson JE, Weiner LB, McMillan JA, Schneider AJ, Rokahr JE 1985 Necrotizing enterocolitis: intraluminal biochemistry in human neonates and a rabbit model. Pediatr Res 19:919-921

28. Clark DA, Miller MJ 1990 Intraluminal pathogenesis of necrotizing enterocolitis. J Pediatr 117:S64-S67

29. Kien CL 1996 Digestion, absorption, and fermentation of carbohydrates in the newborn. Clin Perinatol 23:211-228

30. Pender SL, Quinn JJ, Sanderson IR, MacDonald TT 2000 Butyrate upregulates stromelysin-1 production by intestinal mesenchymal cells. Am J Physiol Gastrointest Liver Physiol 279:G918-G924 